\title{
Neuroactive Steroids in Depression and Anxiety Disorders: Clinical Studies
}

\author{
Daniela Eser ${ }^{a}$ Cornelius Schüle ${ }^{a}$ Thomas C. Baghai ${ }^{a}$ Elena Romeo ${ }^{b}$ \\ Rainer Rupprecht ${ }^{\mathrm{a}}$ \\ a Department of Psychiatry, Ludwig-Maximilian University, Munich, Germany; ${ }^{b}$ Department of Neuroscience, \\ Tor Vergata University, IRCCS Santa Lucia, Rome, Italy
}

\begin{abstract}
Key Words
Neurosteroids $\cdot \gamma$-Aminobutyric acid type A receptor . Ligand-gated ion channel $\cdot$ Antidepressants $\cdot$ Partial sleep deprivation · Transcranial magnetic stimulation • Electroconvulsive therapy · Cholecystokinine-tetrapeptide • Panic disorder
\end{abstract}

\begin{abstract}
Certain neuroactive steroids modulate ligand-gated ion channels via non-genomic mechanisms. Especially $3 \alpha$-reduced pregnane steroids are potent positive allosteric modulators of the $\gamma$-aminobutyric acid type $A\left(G A B A_{A}\right)$ receptor. During major depression, there is a disequilibrium of $3 \alpha$-reduced neuroactive steroids, which is corrected by clinically effective pharmacological treatment. To investigate whether these alterations are a general principle of successful antidepressant treatment, we studied the impact of nonpharmacological treatment options on neuroactive steroid concentrations during major depression. Neither partial sleep deprivation, transcranial magnetic stimulation, nor electroconvulsive therapy affected neuroactive steroid levels irrespectively of the response to these treatments. These studies suggest that the changes in neuroactive steroid concentrations observed after antidepressant pharmacothera-
\end{abstract}

Presented at the Sixth International Congress of Neuroendocrinology, June 19-22, 2006, Pittsburgh, Pa., USA. (c) 2006 S. Karger AG, Basel

$0028-3835 / 06 / 0844-0244 \$ 23.50 / 0$

Fax +41613061234

E-Mail karger@karger.ch

www.karger.com
Accessible online at:

www.karger.com/nen py more likely reflect distinct pharmacological properties of antidepressants rather than the clinical response. In patients with panic disorder, changes in neuroactive steroid composition have been observed opposite to those seen in depression. However, during experimentally induced panic induction either with cholecystokinine-tetrapeptide or sodium lactate, there was a pronounced decline in the concentrations of $3 \alpha$-reduced neuroactive steroids in patients with panic disorder, which might result in a decreased GABAergic tone. In contrast, no changes in neuroactive steroid concentrations could be observed in healthy controls with the exception of $3 \alpha, 5 \alpha$-tetrahydrodeoxycorticosterone. The modulation of $\mathrm{GABA}_{\mathrm{A}}$ receptors by neuroactive steroids might contribute to the pathophysiology of depression and anxiety disorders and might offer new targets for the development of novel anxiolytic compounds.

Copyright $\odot 2006$ S. Karger AG, Basel

\section{Introduction}

In the past decades, considerable evidence has emerged that certain steroids not only act as transcription factors in the regulation of gene expression [1] but may also alter neuronal excitability through interaction with specific neurotransmitter receptors [2-5]. The term 'neuroactive steroids' has been adapted for steroids with these particular properties. Furthermore, a variety of neuroactive steroids may be synthesized de novo from cholesterol in the 


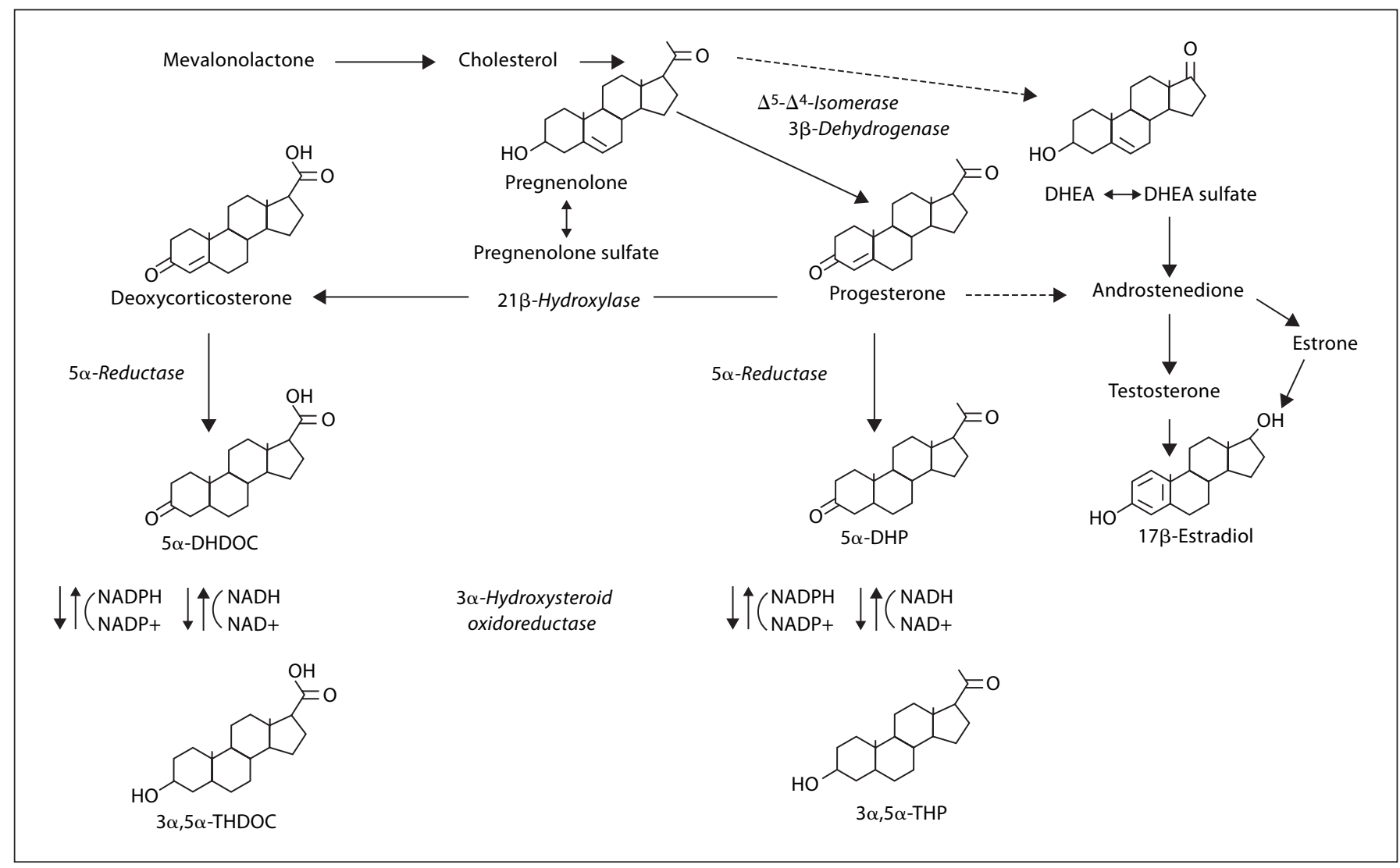

Fig. 1. Biosynthesis of $3 \alpha$-reduced neuroactive steroids. Reproduced with permission from Rupprecht and Holsboer [5].

brain without the aid of peripheral sources [6]. These neuroactive steroids have been defined as 'neurosteroids' [7].

The main precursor molecule for the synthesis of neuroactive steroids is pregnenolone which is a precursor for dehydroepiandrosterone (DHEA). Pregnenolone may also be converted into progesterone which may be further reduced into the $3 \alpha$-pregnane metabolites $5 \alpha$-dihydroprogesterone ( $5 \alpha$-DHP) and $5 \alpha$-dihydrodeoxycorticosterone ( $5 \alpha$-DHDOC). These molecules serve as precursors for the so-called $3 \alpha$-reduced neuroactive steroids $3 \alpha, 5 \alpha$-tetrahydroprogesterone $(3 \alpha, 5 \alpha$-THP; allopregnanolone), $3 \alpha, 5 \beta$-tetrahydroprogesterone $(3 \alpha, 5 \beta$-THP; $5 \beta$-pregnan- $3 \alpha$-ol-20-one) and $3 \alpha, 5 \alpha$-tetrahydrodeoxycorticosterone $(3 \alpha, 5 \alpha$-THDOC; $3 \alpha, 21$-dihydroxy- $5 \alpha-$ pregnan-20-one; allotetrahydrodeoxycorticosterone). In particular, these $3 \alpha$-reduced neuroactive steroids are potent positive allosteric modulators of the $\gamma$-aminobutyric acid type $A\left(G_{A B A}\right)$ receptor because they increase the frequency and/or duration of openings of the GABA-gat- ed chloride channel $[2,4]$. Thereby, $3 \alpha, 5 \alpha$-THDOC derives mainly from the adrenal gland and the synthesis of its precursor deoxycorticosterone (DOC) is under the control of corticotropin (ACTH) (fig. 1). A detailed review on steroid biosynthesis in the central nervous system is given elsewhere [8]. In view of their GABA-enhancing properties, such $3 \alpha$-reduced neuroactive steroids are of major interest for depression and anxiety disorders. In contrast, the sulfate esters of pregnenolone or DHEA display GABA-antagonistic properties $[9,10]$. Although the majority of studies have focused on the modulatory potential of neuroactive steroids at the $\mathrm{GABA}_{\mathrm{A}}$ receptor, also other receptors, for example the $\mathrm{N}$ methyl-D-aspartate-gated ion channel [11] or the $\sigma_{1}$ receptor [12], may be a target for neuroactive steroids. However, in view of their GABA-enhancing properties, $3 \alpha$-reduced neuroactive steroids are of particular interest for neuropsychopharmacological research. Preclinical studies suggested that neuroactive steroids may modulate anxiety and depression-related behavior. Moreover, it has 
been suggested that neuroactive steroids may be involved in the therapeutical effects of antidepressant drugs, and several clinical studies suggested that changes in neuroactive steroid concentrations might be involved in the pathophysiology and course of certain psychiatric disorders. This review will in particular focus on the role of neuroactive steroids in depression and anxiety disorders.

\section{Neuroactive Steroids as Endogenous Modulators of Depression and Anxiety Disorders}

Pregnenolone, the main precursor molecule for steroid hormone and neuroactive steroid synthesis, and its sulfated derivate pregnenolone sulfate (PS) may directly modulate neurotransmitter receptors [13]. Preclinical studies suggested that pregnenolone/PS modulate depression and anxiety-related behavior. PS has been shown to exert an antidepressant-like profile in the forced swimming procedure, probably throughout interaction with $\sigma_{1}$ receptors [14]. In addition, in animal models of anxietyrelated behavior, a biphasic response curve has been shown for PS [15], being anxiogenic at higher and anxiolytic at lower doses [15]. This effect is compatible with a demonstrated mixed agonistic/antagonistic profile at $\mathrm{GABA}_{\mathrm{A}}$ receptors [16-18]. In line with these preclinical results, a pathophysiological role of pregnenolone and its sulfate conjugate has been suggested in affective disorders. Decreased PS levels have been found in patients suffering from depression [19], generalized anxiety disorder [20] and generalized social phobia [21]. In contrast, in women suffering from mixed anxiety-depressive disorder [22] or from premenstrual syndrome (PMS) [23], elevated PS plasma concentrations have been observed, suggesting that the pattern of dysregulated pregnenolone/PS levels may vary with different psychiatric disorders.

Because of certain similarities concerning the molecular mechanisms of PS and DHEA/DHEA sulfate (DHEAS), similar effects on depression and anxiety-related behavior might be expected. Like PS, also DHEAS has been shown to exert antidepressant-like effects in the forced swimming procedure, which are mediated throughout interaction with $\sigma_{1}$ receptors $[14,24]$. In addition, compatible with a positive allosteric modulation of $\mathrm{GABA}_{\mathrm{A}}$ receptors at lower concentrations, DHEA/ DHEAS showed anxiolytic activity in the plus maze test in mice [25].

In humans, a variety of studies focused on DHEA/ DHEAS plasma levels as an additional neuroendocrino- logical marker of depression. However, these studies revealed inconsistent results. In patients suffering from depression, decreased DHEAS plasma levels $[26,27]$ and DHEA salivary concentrations [28] have been observed. In contrast, other studies reported significant elevations of DHEAS 24-hour urinary levels [29] and diurnal minimal and mean DHEA plasma concentrations [30].

In addition, amelioration of depressive symptomatology has been associated with a decrease in DHEA/DHEAS levels. In patients suffering from depression, elevated DHEAS plasma levels decreased after antidepressant pharmacotherapy [31]. Furthermore, recently, remission of late-life depression has been associated with a decline in DHEA/DHEAS levels, an effect that was not observed in nonremitted patients [28]. In line with these observations, elevated baseline concentrations of DHEAS have been shown to predict nonresponse to electroconvulsive therapy (ECT) in depressed psychotic patients [32].

In line with a GABA-enhancing potential, anxiolytic effects of progesterone, the main precursor molecule for $3 \alpha$-reduced neuroactive steroids, have been shown in several preclinical trials. It has been suggested that the in vivo conversion of progesterone into $3 \alpha$-pregnane steroids accounts for its anxiolytic effects and not the direct interaction with intracellular progesterone receptors. Progesterone elicited anxiolytic effects in ovarectomized rats [33] and in mice lacking intracellular progesterone receptors [34]. These anxiolytic effects of progesterone were accompanied by an increase in $3 \alpha, 5 \alpha$-THP concentrations $[33,34]$, suggesting that the anxiolytic properties of progesterone are mediated by its in vivo conversion to the $3 \alpha$-reduced metabolite [33].

In humans, a pathophysiological role of progesterone has been suggested in anxiety disorders. In women suffering from panic disorder, an increase in progesterone levels has been reported during the midluteal phase of the menstrual cycle [35], where phobic symptomatology improved significantly [35]. Thus, the menstrual cycle-related surge of progesterone and its GABAergic metabolites might contribute to the clinical amelioration of panic disorder [35]. Furthermore, compared with healthy controls, progesterone plasma concentrations have been found to be elevated in drug-free male panic disorder patients and have been suggested to reflect a counterregulatory defense mechanism against the occurrence of panic attacks [36]. In addition, progesterone plasma levels have been shown to correlate significantly with state anxiety scores in healthy males [37] and in men suffering from panic disorder [36]. However, no association has been found in women suffering from panic disorder [35], 
thereby suggesting that the anxiety modulatory action of neuroactive steroids might depend on gender [36].

In view of their GABA-enhancing properties, the majority of preclinical studies focused on possible anxiolytic properties of $3 \alpha$-reduced neuroactive steroids. In different animal models of anxiety-related behavior, a clear anxiolytic profile has been shown for $3 \alpha, 5 \alpha$-THP and $3 \alpha, 5 \beta$-THP [38-43]. A similar anxiolytic potential has been demonstrated for the peripheral $3 \alpha$-pregnane steroid $3 \alpha, 5 \alpha$-THDOC $[41,42,44]$. Although first studies investigating $3 \alpha$-reduced neuroactive steroid levels in anxiety disorders found no differences in $3 \alpha, 5 \alpha$-THP levels between patients suffering from mixed anxiety-depressive disorder [22], generalized anxiety disorder [20] or generalized social phobia [45] and healthy controls, first studies of our research group in patients with panic disorder suggested that $3 \alpha$-reduced neuroactive steroids may play a pivotal role in human anxiety.

Compared with healthy controls, plasma concentrations of $3 \alpha$-reduced neuroactive steroids were elevated, while the concentrations of $3 \beta, 5 \alpha-\mathrm{THP}$, an antagonistic stereoisomer of $3 \alpha, 5 \alpha$-THP, were decreased [46]. In line with this finding, in women suffering from panic disorder and agoraphobia, increased plasma concentrations of $3 \alpha, 5 \alpha$-THP have been observed during the early follicular and premenstrual phase [35]. The observed elevations of $3 \alpha$-reduced neuroactive steroids and the concomitant decrease in the functional GABA-antagonistic isomer in panic disorder patients in the absence of panic attacks might be interpreted as endogenous counterregulatory mechanisms against the occurrence of spontaneous panic attacks [47]. This hypothesis was further supported by our studies investigating neuroactive steroid concentrations during experimental panic induction, which is a well-established model for the pathophysiology of panic disorder.

Experimental panic induction was followed by pronounced changes in neuroactive steroid concentrations, which were indeed the opposite to those seen in panic disorder patients in the absence of panic attacks. Challenge with sodium lactate or cholecystokinin-tetrapeptide (CCK-4) was accompanied by a significant decrease in $3 \alpha, 5 \alpha$-THP and $3 \alpha, 5 \beta$-THP concentrations and a concomitant increase in $3 \beta, 5 \alpha$-THP levels in patients with panic disorder [48], compatible with a decreased GABAergic tone during panic attacks. In contrast, no such changes in neuroactive steroid compositions following challenge with sodium lactate or CCK-4 could be detected in healthy controls [48], even if subjects exhibited a comparable level of CCK-4-induced panic anxiety [49].
Therefore, the observed alterations in neuroactive steroid levels in patients with panic disorder during experimental panic induction do not merely reflect the level of anxiety but appear to be related to the pathophysiology of panic attacks in panic disorder $[48,49]$.

However, panic induction with CCK-4, which is known to elicit a marked stimulation of cortisol and ACTH release [50], was accompanied by a significant rise in $3 \alpha, 5 \alpha-$ THDOC levels in healthy controls [51] (fig. 2). As preclinical data suggested a role for $3 \alpha, 5 \alpha$-THDOC in the regulation and termination of the endogenous stress response [52], the observed rise in $3 \alpha, 5 \alpha$-THDOC levels might be a consequence of the CCK-4-induced ACTH release and might contribute to the termination of the panic/stress response following challenge with CCK- 4 in humans.

In addition to the observed alterations in $3 \alpha$-reduced neuroactive steroids in panic disorder, increasing evidence comes from preclinical and clinical studies that $3 \alpha$-reduced neuroactive steroids play an important role as endogenous modulators of major depression. In different animal models of depression-related behavior, a dysregulation of $3 \alpha$-reduced neuroactive steroids has been observed, which has been suggested to constitute a pathophysiological factor in the development of depression-related behavior. Protracted social isolation in mice is followed by a behavioral adaptation syndrome and a decreased response to GABAergic drugs, which shares some features of depression. In the frontal cortex of such animals, the concentrations of $3 \alpha, 5 \alpha$-THP and $5 \alpha$-DHP were decreased $[53,54]$ due to a diminished expression of $5 \alpha$-reductase type I protein and mRNA [53], suggesting that a dysregulated biosynthesis of $3 \alpha$-reduced neuroactive steroids might contribute to the behavioral and neurochemical alterations found in this mouse model of depression [54, 55].

Olfactory bulbectomy represents a further rodent paradigm for depression. After olfactory bulbectomy, a significant decline in $3 \alpha, 5 \alpha$-THP levels has been observed in distinct cerebrocortical areas [56] concurrently with the development of behavioral, neurochemical and neuroendocrine changes, which might contribute to the development of the depression-related bulbectomy syndrome [56]. Thus, the decline in $3 \alpha, 5 \alpha$-THP levels might reflect a distinct pathophysiological mechanism underlying the depression-related behavioral alterations in the bulbectomy syndrome [56].

In line with these preclinical investigations, alterations in $3 \alpha$-pregnane neuroactive steroids have been observed in humans suffering from major depression. In two independent samples of depressive patients, decreased levels of $3 \alpha$-reduced neuroactive steroids have been found both in 


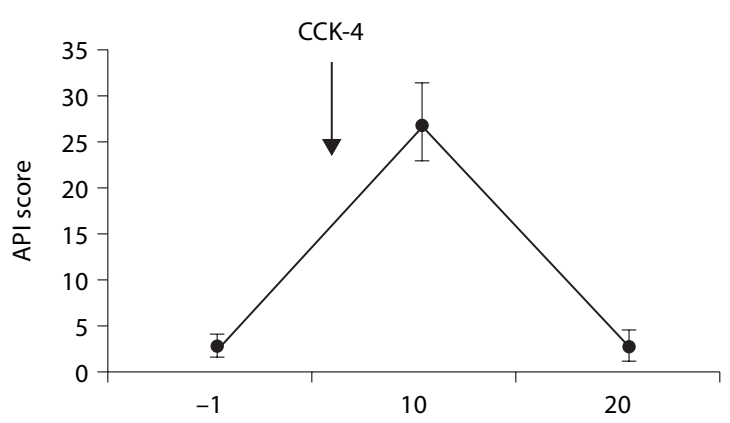

a

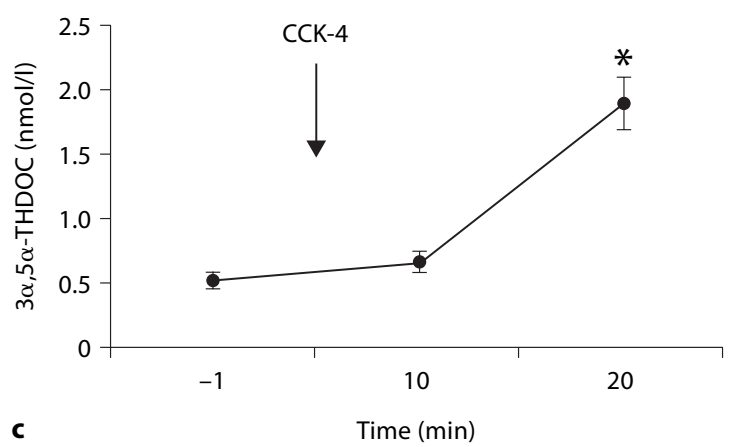

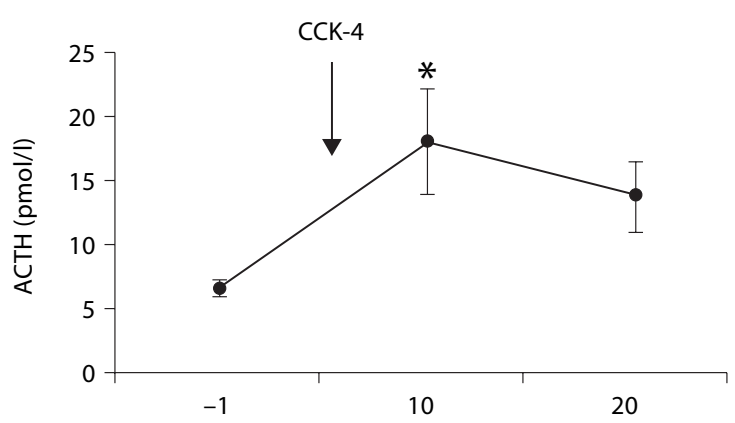

b

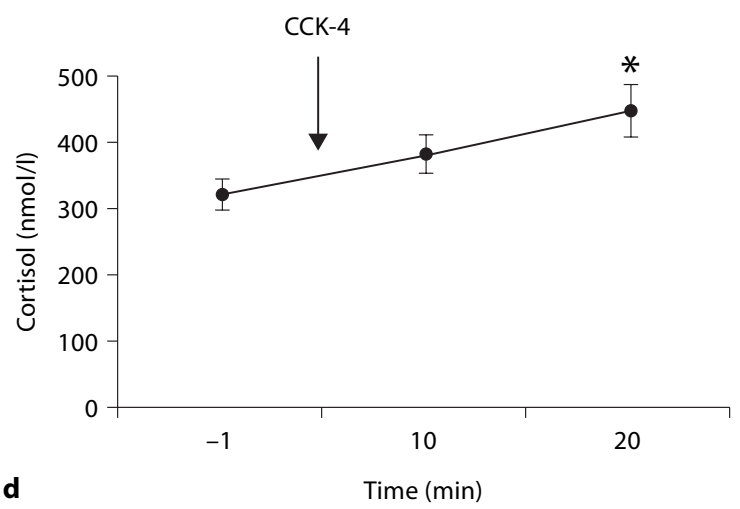

Fig. 2. Panic response (acute panic inventory score; API) (a) and plasma concentrations of ACTH (b), $3 \alpha, 5 \alpha-$ THDOC (c) and cortisol (d) in healthy controls before (-1 min) and after experimental panic induction with $50 \mu \mathrm{g}$ CCK-4 (10-20 min after challenge). Data are presented as mean \pm SEM. ${ }^{*}$ Statistical significance at the $\mathrm{p}<0.05$ level in post hoc tests following MANOVA. Reproduced with permission from Eser et al. [51].

plasma [57] and in cerebrospinal fluid (CSF) [58]. The concentrations of $3 \alpha, 5 \alpha$-THP and $3 \alpha, 5 \beta$-THP were reduced in plasma and CSF, while there was an increase in $3 \beta, 5 \alpha$-THP, which may act as a functional antagonist for those GABA-agonistic steroids [57]. Furthermore, $3 \alpha, 5 \alpha$ THDOC plasma levels were found to be elevated during depression, probably as a consequence of hypothalamicpituitary-adrenal axis overdrive [59].

\section{Therapeutic Potential of Neuroactive Steroids in the Treatment of Major Depression and Anxiety Disorders}

\section{Therapeutic Properties of Synthetic Derivates of}

Neuroactive Steroids

Corresponding to preclinical data suggesting antidepressive and anxiolytic effects of exogenously adminis- tered pregnenolone and PS, first clinical investigations evaluated the putative therapeutical effects of pregnenolone in humans. Although the first study in healthy volunteers revealed no improvement in mood, memory, self-rated sleep quality or subjective well-being after 4 weeks of treatment with pregnenolone [60], a tendency for pregnenolone to reduce subjective depression ratings was observed [60]. Furthermore, in an additional subgroup analysis, pregnenolone significantly reduced the sedative effects of a single dose of diazepam [60]. In this context, it was hypothesized that pregnenolone, due to its $\mathrm{GABA}_{\mathrm{A}}$ receptor antagonistic profile, might antagonize acute benzodiazepine effects, and therefore, might be of putative benefit for the treatment of certain psychiatric conditions [60].

In line with observed alterations in DHEA/DHEAS levels in depressed patients, first studies investigating the therapeutical effects of DHEA revealed promising results in the treatment of major depression. Already the first 
open-label study demonstrated a significant improvement in depressive symptoms after 6 months of DHEA therapy [61]. Further double-blind placebo-controlled trials confirmed these results. In midlife-onset dysthymia, $60 \%$ of the patients responded to treatment with DHEA after 6 weeks [62]. Furthermore, administration of DHEA either as a monotherapy or as an augmentation to stable antidepressant regimens significantly decreased depressive symptoms in unipolar and bipolar depression [63]. Recently, it has been demonstrated that even monotherapy with DHEA significantly improved symptoms of minor and major midlife-onset depression [64].

So far, putative therapeutic properties of DHEAS have not been investigated in anxiety disorders. However, in schizophrenic patients additionally treated with DHEA, anxiety symptoms improved [65], thereby suggesting that this neurosteroid may also possess beneficial effects in the treatment of anxiety-related symptoms.

Clinical studies concerning putative therapeutical effects of progesterone in major depression or anxiety disorders are lacking so far. Nevertheless, administration of progesterone might constitute a supplementary treatment strategy for several clinical symptoms found in depression, as progesterone exerts pronounced GABAergic effects on sleep [66]. In addition, several studies focused on the putative beneficial effects of progesterone administration in patients suffering from PMS, which in part overlaps with depressive symptomatology. While some investigations reported an improvement in mood [67-69] in women suffering from PMS, others found no superiority to placebo treatment [70-72]. Furthermore, the previously recommended prophylactic postpartum use of progesterone in women who had experienced postpartum depression in the past [73] was challenged by an observed enhanced risk of postpartum depression after progesterone therapy [74]. Thus, no definite conclusion can be drawn at the moment as to whether or not synthetic progestins might constitute a useful strategy for the treatment of anxiety or depression [75].

\section{Modulation of Endogenous Neuroactive Steroid Levels as a Putative Pharmacological Mechanism of Antidepressant Drugs}

Preclinical studies suggested that neuroactive steroids may not only directly modulate anxiety and depressionrelated behavior but that neuroactive steroids may also be involved in the therapeutical effects of antidepressant drugs. Most evidence for this suggestion came from stud- ies investigating the impact of antidepressant treatment on endogenous $3 \alpha$-reduced neuroactive steroid levels.

In the depression-related olfactory bulbectomy model, chronic treatment with three different classes of antidepressants reversed the decline in $3 \alpha, 5 \alpha$-THP levels in rats after 3 weeks [76]. This time interval is typically necessary to counteract the depression-related behavioral deficits of the bulbectomy syndrome by pharmacological treatment [76]. Therefore, it has been suggested that normalization of $3 \alpha, 5 \alpha$-THP levels might contribute to the therapeutic effects of various antidepressants in this animal model of depression [76]. However, the molecular mechanisms underlying the effects of antidepressant drugs on neuroactive steroid concentrations are still under investigation.

Acute administration of the selective serotonin reuptake inhibitor (SSRI) fluoxetine in rats was followed by a significant increase in $3 \alpha, 5 \alpha$-THP in different brain regions $[77,78]$ and a concomitant decrease in the precursor molecule $5 \alpha$-DHP [77]. In contrast, the tricyclic antidepressant imipramine had no effect on neuroactive steroid concentrations [77], suggesting a specific action of fluoxetine on $3 \alpha$-hydroxysteroid dehydrogenase ( $3 \alpha-$ HSD), the enzyme that catalyses the conversion of $5 \alpha-$ DHP to $3 \alpha, 5 \alpha$-THP [77]. This hypothesis was supported by the finding that SSRIs but not tricyclic antidepressants shift the activity of the $3 \alpha-H S D$ towards the reductive direction [79], thereby enhancing the efficiency of the conversion of $5 \alpha$-DHP to $3 \alpha, 5 \alpha$-THP [79], although these findings were not confirmed in another study [80]. Furthermore, preclinical studies investigating the effects of mirtazapine on neuroactive steroid composition revealed conflicting results. Mirtazapine is an antidepressant which acts as an antagonist of $\alpha_{2}, 5-\mathrm{HT}_{2}, 5-\mathrm{HT}_{3}$ and histamine $\mathrm{H}_{1}$ receptors, a mechanism different from SSRIs and tricyclic antidepressants. Single injections of mirtazapine increased $3 \alpha, 5 \alpha$-THP brain and plasma levels, while mirtazapine long-term administration did not affect neuroactive steroid levels [81]. However, recently, we were able to demonstrate a dose-dependent inhibitory effect of mirtazapine on the activity of a microsomal $3 \alpha-$ HSD [82]. Although $3 \alpha-H S D$ can act bidirectionally in vitro, in the living brain, due to the intracellular availability of respective cofactors, cytosolic $3 \alpha-\mathrm{HSD}$ is expected to almost exclusively catalyze the conversion of $5 \alpha$-DHP into $3 \alpha, 5 \alpha$-THP (reductive pathway), whereas microsomal $3 \alpha-\mathrm{HSD}$ is expected to catalyze the conversion of $3 \alpha, 5 \alpha$-THP into $5 \alpha$-DHP (oxidative pathway) [82]. Mirtazapine did not affect the reductive direction but inhibited a microsomal isoform of $3 \alpha-H S D$, thereby 
inhibiting the oxidation of $3 \alpha, 5 \alpha$-THP into $3 \alpha$-DHP (fig. 3). This effect is compatible with an enhanced formation of $3 \alpha$-reduced neuroactive steroids similar to the effect of SSRIs [82].

In depressed patients, a variety of studies suggested that antidepressant drugs might correct the observed disequilibrium in $3 \alpha$-reduced neuroactive steroid composition and that this correction might contribute to the therapeutical effects of antidepressant drugs. Administration of fluoxetine has been shown to increase $3 \alpha, 5 \alpha-$ THP and $3 \alpha, 5 \beta$-THP plasma [57] and CSF levels [58] and to concomitantly decrease $3 \beta, 5 \alpha$-THP concentrations in patients suffering from depression [57]. However, in contrast to preclinical data, treatment with tricyclic antidepressants influenced $3 \alpha, 5 \alpha$-THP, $3 \alpha, 5 \beta$-THP and $3 \beta, 5 \alpha$-THP levels in a similar way to SSRIs [57].

To answer the question whether changes in neuroactive steroid concentrations contribute to the clinical effects of antidepressant treatment or whether they are related to specific pharmacological properties of antidepressant drugs, our group investigated the impact of different nonpharmacological treatment strategies on neuroactive steroid concentrations in major depression.

Partial sleep deprivation (PSD), which is known to rapidly but only transiently ameliorate depressive symptoms, was applied in depressed inpatients as a monotherapy. Neuroactive steroid levels were determined the day before and after PSD and after one night of recovery sleep [83]. PSD ameliorated depressive symptoms in the majority of patients, although this therapeutical effect was only transient and followed by a relapse of symptoms the day after recovery sleep. Nonresponders compared with responders showed significantly higher plasma concentrations of $3 \alpha, 5 \alpha$-THP and $3 \alpha, 5 \beta$-THP before and after PSD; however, no alterations in neuroactive steroid levels could be detected after PSD in either group [83].

In addition, we investigated the impact of repetitive transcranial magnetic stimulation (rTMS) as a mediumterm nonpharmacological treatment strategy [84]. However, even though about half of the patients significantly improved after 2 weeks of rTMS monotherapy, no alterations in $3 \alpha, 5 \alpha$-THP, $3 \alpha, 5 \beta$-THP and $3 \beta, 5 \alpha$-THP levels could be found either in responders or nonresponders [84], suggesting that the antidepressive effects of this medium-term biological treatment strategy are not linked to alterations in $3 \alpha$-reduced neuroactive steroid levels. Finally, to rule out the possibility that the antidepressive effects of PSD or rTMS may have been too weak to interfere with neuroactive steroid concentrations, the impact of ECT was studied on neuroactive steroids. ECT is still

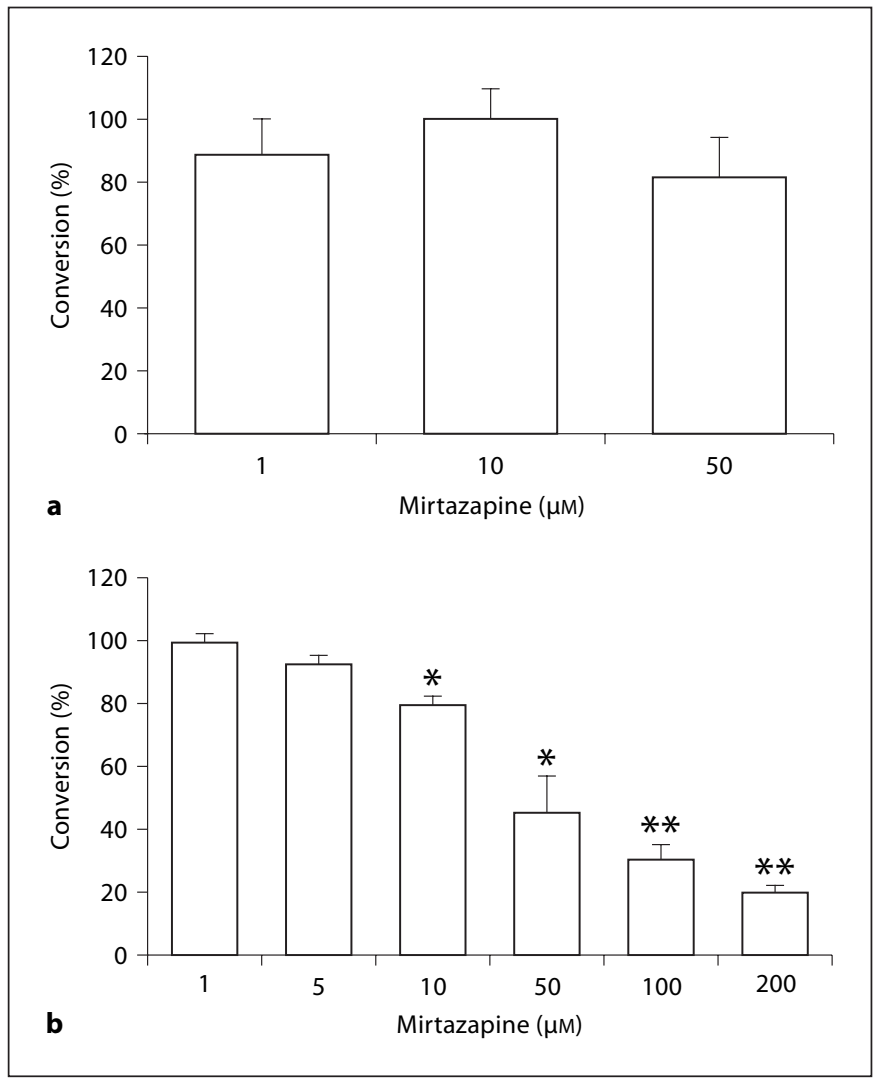

Fig. 3. Impact of mirtazapine at different concentrations on the activities of both human cytosolic $3 \alpha$-HSD type 3 (reductive pathway) (a) and human microsomal $3 \alpha$-HSD (oxidative pathway) (b). Data are presented as means \pm SEM of at least 3 independent experiments and are indicated as percentage of vehicle (conversion rates obtained in the vehicle are set at 100\%). * Statistical significance at $\mathrm{p}<0.05 ;{ }^{*}$ statistical significance at $\mathrm{p}<$ 0.001. Reproduced with permission from Schule et al. [82].

considered as the most effective biological treatment strategy in severe treatment-resistant major depression. Neuroactive steroids were quantified in 31 pharmacotherapy-resistant depressed patients before and after 4 weeks of ECT [85]. Sixteen out of 31 patients responded to ECT and about half of those patients achieved a full remission from major depression. However, remitters, responders and nonresponders did not differ in neuroactive steroid levels nor did ECT influence $3 \alpha, 5 \alpha$-THP, $3 \alpha, 5 \beta$-THP and $3 \beta, 5 \alpha$-THP concentrations [85].

Therefore, in contrast to the previously reported changes in $3 \alpha$-reduced neuroactive steroid concentrations following antidepressant pharmacotherapy, none of the investigated nonpharmacological treatment strategies had any impact on neuroactive steroid levels despite 

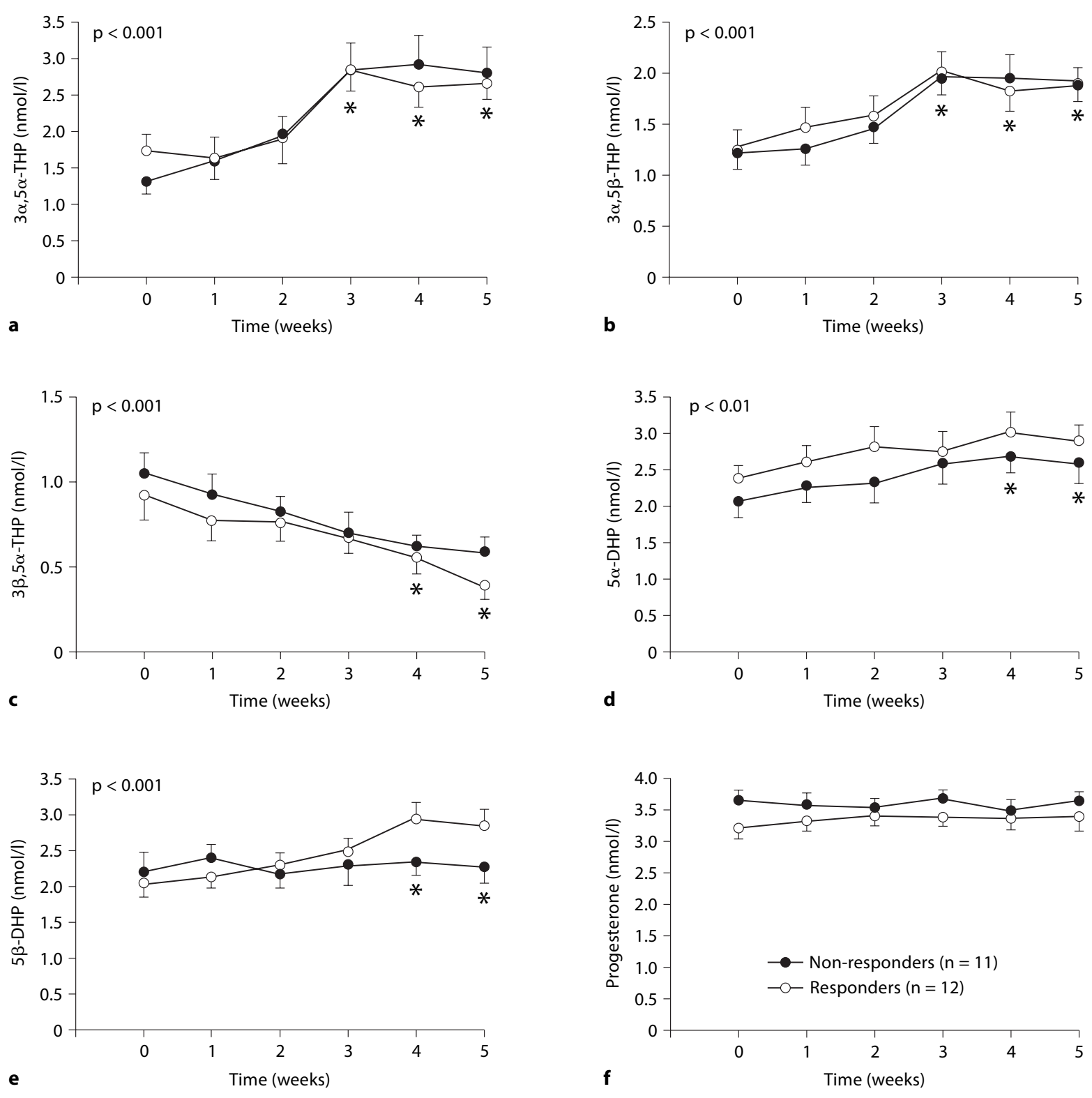

Fig. 4. Plasma concentrations of $3 \alpha, 5 \alpha$-THP (a), $3 \alpha, 5 \beta$-THP (b), $3 \beta, 5 \alpha$-THP (c), $3 \alpha$-DHP (d), $5 \beta$-DHP (e) and progesterone (f) in nonresponders and responders to mirtazapine treatment on week 0 up to week 5 . Data represent means \pm SEM. ${ }^{*}$ Significant difference compared with week 0 in test with contrasts. Reproduced with permission from Schule et al. [82].

a pronounced antidepressive effect. These findings confirmed the hypothesis that the observed alterations in neuroactive steroid concentrations following antidepressant pharmacotherapy are indeed related to specific pharmacological properties of antidepressant drugs.
Furthermore, our research group recently investigated the impact of mirtazapine monotherapy on neuroactive steroid composition in patients suffering from major depression. We found increased $3 \alpha, 5 \alpha$-THP, $3 \alpha, 5 \beta$-THP, $5 \alpha$-DHP and $5 \beta$-DHP concentrations, whereas $3 \beta, 5 \alpha-$ 
THP levels decreased after 5 weeks of mirtazapine monotherapy [82]. However, these changes in neuroactive steroid concentrations were comparable in responders and nonresponders and were not correlated to the clinical response (fig. 4). Therefore, so far, our data do not support the hypothesis that the normalization of endogenous neuroactive steroid levels is essential for the clinical response in the treatment of depression, and a lack of effect on neuroactive steroid concentrations, as noted after nonpharmacological treatment, does not preclude antidepressive efficacy.

Nevertheless, the interference with neuroactive steroid composition still constitutes a promising new pharmacological treatment strategy in depression and anxiety disorders as preclinical data suggested beneficial effects of new mitochondrial benzodiazepine receptor (MBR) ligands. The biosynthesis of GABAergic neuroactive steroids, which is under the control of the MBR [86], might be enhanced throughout treatment with specific MBR agonists [86], and these MBR agonists have been shown to exert pronounced anxiolytic effects in animal models without sedation and abuse liability [86, 87].

\section{Conclusion}

There is considerable preclinical and clinical evidence that neuroactive steroids are important endogenous modulators of depression and anxiety-related behavior and might have therapeutic potential for the treatment of depression and anxiety disorders. A definitive proof whether neuroactive steroids have indeed a therapeutical potential for the treatment of affective disorders and are superior to already existing psychopharmacological drugs will come from systematic clinical studies in this new area of research. Such novel therapeutic strategies might either be based on synthetic derivates of endogenous neuroactive steroids or on the modulation of neurosteroid synthesis either by classical antidepressants or other compounds interfering with neurosteroidogenic enzymes. Additionally, the peripheral benzodiazepine receptor may constitute a further target to influence the equilibrium of endogenous neuroactive steroids.

Furthermore, it remains to be elucidated whether neuroactive steroids may serve as biomarkers in the differential diagnosis of affective disorders. However, in this context, it has to be determined to what extent neuroactive steroid plasma levels essentially reflect brain concentrations. Although it has been suggested that plasma levels are likely to reflect brain levels, because neuroactive steroids can easily cross the blood brain barrier, this does not exclude the possibility of local alterations in brain concentrations of neuroactive steroids that are not detected by plasma or CSF measurements. Therefore, further research is needed to develop highly sensitive and specific technologies of neurosteroid determination, which are both economical and of reasonable labor intensity.

\section{References}

1 Evans RM: The steroid and thyroid hormone receptor superfamily. Science 1988;240: 889-895.

2 Lambert JJ, Belelli D, Hill-Venning C, Peters JA: Neurosteroids and $\mathrm{GABA}_{\mathrm{A}}$ receptor function. Trends Pharmacol Sci 1995;16: 295-303.

3 Majewska MD, Harrison NL, Schwartz RD, Barker JL, Paul SM: Steroid hormone metabolites are barbiturate-like modulators of the GABA receptor. Science 1986;232:10041007.

4 Paul SM, Purdy RH: Neuroactive steroids. FASEB J 1992;6:2311-2322.

5 Rupprecht R, Holsboer F: Neuroactive steroids: mechanisms of action and neuropsychopharmacological perspectives. Trends Neurosci 1999;22:410-416.

6 Akwa Y, Morfin RF, Robel P, Baulieu EE: Neurosteroid metabolism. $7 \alpha$-Hydroxylation of dehydroepiandrosterone and pregnenolone by rat brain microsomes. Biochem J 1992;288:959-964.
7 Baulieu EE: Neurosteroids: a new function in the brain. Biol Cell 1991;71:3-10.

8 Mensah-Nyagan AG, Do-Rego JL, Beaujean D, Luu-The V, Pelletier G, Vaudry H: Neurosteroids: expression of steroidogenic enzymes and regulation of steroid biosynthesis in the central nervous system. Pharmacol Rev 1999;51:63-81.

9 Majewska MD, Mienville JM, Vicini S: Neurosteroid pregnenolone sulfate antagonizes electrophysiological responses to GABA in neurons. Neurosci Lett 1988;90: 279-284.

10 Majewska MD, Demigören S, Spivak CE, London ED: The neurosteroid dehydroepiandrosterone sulfate is an allosteric antagonist of the $\mathrm{GABA}_{\mathrm{A}}$ receptor. Brain Res 1990; 526:143-146.

11 Wu FS, Gibbs TT, Farb DH: Pregnenolone sulfate: a positive allosteric modulator at the $\mathrm{N}$-methyl-D-aspartate receptor. Mol Pharmacol 1991;40:333-336.
12 Monnet FP, Mahé V, Robel P, Baulieu EE: Neurosteroids, via sigma receptors, modulate the $\left[{ }^{3} \mathrm{H}\right]$ norepinephrine release evoked by $\mathrm{N}$-methyl-D-aspartate in the rat hippocampus. Proc Natl Acad Sci USA 1995;92: 3774-3778.

13 Rupprecht R: The neuropsychopharmacological potential of neuroactive steroids. J Psychiatr Res 1997;31:297-314.

14 Reddy DS, Kaur G, Kulkarni SK: Sigma $\left(\sigma_{1}\right)$ receptor mediated antidepressant-like effects of neurosteroids in the Porsolt forced swim test. Neuroreport 1998;9:3069-3073.

15 Melchior CL, Ritzmann RF: Pregnenolone and pregnenolone sulfate, alone and with ethanol, in mice on plus-maze. Pharmacol Biochem Behav 1994;48:893-897.

16 Majewska MD, Bluet-Pajot MT, Robel P, Baulieu EE: Pregnenolone sulfate antagonizes barbiturate-induced hypnosis. Pharmacol Biochem Behav 1989;33:701-703. 
17 Majewska MD: Neurosteroids: endogenous bimodal modulators of the $\mathrm{GABA}_{\mathrm{A}}$ receptor. Mechanism of action and physiological significance. Prog Neurobiol 1992;38:379-395.

18 Mienville JM, Vicini S: Pregnenolone sulfate antagonizes $\mathrm{GABA}_{\mathrm{A}}$ receptor-mediated currents via a reduction of channel opening frequency. Brain Res 1989;489:190-194.

19 George MS, Guidotti A, Rubinow D, Pan B, Mikalauskas K, Post RM: CSF neuroactive steroids in affective disorders: pregnenolone, progesterone and DBI. Biol Psychiatry 1994;35:775-780.

20 Semeniuk T, Jhangri GS, Le Melledo JM: Neuroactive steroid levels in patients with generalized anxiety disorder. J Neuropsychiatry Clin Neurosci 2001;13:396-398.

21 Heydary B, Le Melledo JM: Low pregnenolone sulfate plasma levels in patients with social anxiety disorder. Psychol Med 2001;32: 929-933.

22 Bicikova M, Tallová J, Hill M, Krausova Z, Hampl R: Serum concentrations of some neuroactive steroids in women suffering from mixed anxiety-depressive disorder. Neurochem Res 2000;25:1623-1627.

23 Wang M, Seippel L, Purdy RH, Bäckström T: Relationship between symptom severity and steroid variation in women with premenstrual syndrome: study on serum pregnenolone, pregnenolone sulfate, $5 \alpha$-pregnane3,20 -dione and $3 \alpha$-hydroxy- $5 \alpha$-pregnan20-one. J Clin Endocrinol Metab 1996;81: 1076-1082.

24 Urani A, Roman FJ, Phan VL, Su TP, Maurice $\mathrm{T}$ : The antidepressant-like effect induced by $\sigma_{1}$-receptor agonists and neuroactive steroids in mice submitted to the forced swimming test. J Pharmacol Exp Ther 2001; 298:1269-1279.

25 Melchior CL, Ritzmann RF: Dehydroepiandrosterone is an anxiolytic in mice on the plus maze. Pharmacol Biochem Behav 1994; 47:437-441.

26 Barrett-Connor E, von Muhlen D, Laughlin GA, Kripke A: Endogenous levels of dehydroepiandrosterone sulfate, but not other sex hormones, are associated with depressed mood in older women: the Rancho Bernardo Study. J Am Geriatr Soc 1999;47:685-691.

27 Goodyer IM, Herbert J, Altham PM: Adrenal steroid secretion and major depression in 8to 16-year-olds. 3. Influence of cortisol/ DHEA ratio at presentation on subsequent rates of disappointing life events and persistent major depression. Psychol Med 1998;28: 265-273.

28 Fabian TJ, Dew MA, Pollock BG, Reynolds CF, Mulsant BH, Butters MA, Zmuda MD, Linares AM, Trottini M, Kroboth PD: Endogenous concentrations of DHEA and DHEA-S decrease with remission of depression in older adults. Biol Psychiatry 2001;50: 767-774.
29 Tollefson GD, Haus E, Garvey MJ, Evans M, Tuason VB: 24-hour urinary dehydroepiandrosterone sulfate in unipolar depression treated with cognitive and/or pharmacotherapy. Ann Clin Psychiatry 1990;2:39-45.

30 Heuser I, Deuschle M, Luppa P, Schweiger U, Standhardt H, Weber B: Increased diurnal plasma concentrations of dehydroepiandrosterone in depressed patients. J Clin Endocrinol Metab 1998;83:3130-3133.

31 Takebayashi M, Kagaya A, Uchitomi Y, Kugaya A, Muraoka M, Yokota N, Horiguchi J, Yamawaki S: Plasma dehydroepiandrosterone sulfate in unipolar major depression. Short communication. J Neural Transm 1998;105:537-542.

32 Maayan R, Yagorowski Y, Grupper D, Weiss M, Shtaif B, Kaoud MA, Weizman A: Basal plasma dehydroepiandrosterone sulfate level: a possible predictor for response to electroconvulsive therapy in depressed psychotic inpatients. Biol Psychiatry 2000;48: 693-701.

33 Bitran D, Purdy RH, Kellogg CK: Anxiolytic effect of progesterone is associated with increases in cortical allopregnanolone and $\mathrm{GABA}_{\mathrm{A}}$ receptor function. Pharmacol Biochem Behav 1993;45:423-428.

34 Reddy DS, O'Malley BW, Rogawski MA: Anxiolytic activity of progesterone in progesterone receptor knockout mice. Neuropharmacology 2005;48:14-24.

35 Brambilla F, Biggio G, Pisu MG, Bellodi L, Perna G, Bogdanovich-Djukic V, Purdy RH, Serra M: Neurosteroid secretion in panic disorder. Psychiatry Res 2003;118:107-116.

36 Brambilla F, Mellado C, Alciati A, Pisu MG, Purdy RH, Zanone S, Perini G, Serra M, Biggio G: Plasma concentrations of anxiolytic neuroactive steroids in men with panic disorder. Psychiatry Res 2005;135:185-190.

37 Brambilla F, Biggio G, Pisu MG, Purdy RH, Gerra G, Zaimovich A, Serra M: Plasma concentrations of anxiolytic neurosteroids in men with normal anxiety scores: a correlation analysis. Neuropsychobiology 2004;50: 6-9.

38 Akwa Y, Purdy RH, Koob GF, Britton KT: The amygdala mediates the anxiolytic-like effect of the neurosteroid allopregnanolone in rat. Behav Brain Res 1999;106:119-125.

39 Bitran D, Hilvers RJ, Kellogg CK: Anxiolytic effects of $3 \alpha$-hydroxy- $5 \alpha[\beta]$-pregnan-20one: endogenous metabolites of progesterone that are active at the $\mathrm{GABA}_{\mathrm{A}}$ receptor. Brain Res 1991;561:157-161.

40 Reddy DS, Kulkarni SK: Differential anxiolytic effects of neurosteroids in the mirrored chamber behavior test in mice. Brain Res 1997;752:61-71.

41 Rodgers RJ, Johnson NJ: Behaviorally selective effects of neuroactive steroids on plusmaze anxiety in mice. Pharmacol Biochem Behav 1998;59:221-232.
42 Wieland S, Lan NC, Mirasedeghi S, Gee KW: Anxiolytic activity of the progesterone me-

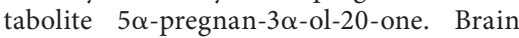
Res 1991;565:263-268

43 Wieland S, Belluzi JD, Stein L, Lan NC: Comparative behavioral characterization of the neuroactive steroids $3 \alpha-\mathrm{OH}, 5 \alpha$-pregnan-20one and $3 \alpha-\mathrm{OH}, 5 \beta$-pregnan-20-one in rodents. Psychopharmcol 1995;118:65-71.

44 Crawley JN, Glowa JR, Majewska MD, Paul SM: Anxiolytic activity of an endogenous adrenal steroid. Brain Res 1986;398:382385

45 Heydari B, Le Melledo JM: Low pregnenolone sulphate plasma concentrations in patients with generalized social phobia. Psychol Med 2002;32:929-933.

46 Ströhle A, Romeo E, di Michele F, Pasini A, Yassouridis A, Holsboer F, Rupprecht R: $\mathrm{GABA}_{\mathrm{A}}$ receptor modulatory neuroactive steroid composition in panic disorder and during paroxetine treatment. Am J Psychiatry 2002;159:145-147.

47 Rupprecht R: Neuroactive steroids: mechanisms of action and neuropsychopharmacological properties. Psychoneuroendocrinology 2003;28:139-168.

48 Strohle A, Romeo E, di Michele F, Pasini A, Hermann B, Gajewsky G, Holsboer F, Rupprecht R: Induced panic attacks shift $\gamma$-aminobutyric acid type A receptor modulatory neuroactive steroid composition in patients with panic disorder: preliminary results. Arch Gen Psychiatry 2003;60:161-168.

49 Zwanzger P, Eser D, Padberg F, Baghai TC, Schule C, Rupprecht R, di Michele F, Romeo E, Pasini A, Strohle A: Neuroactive steroids are not affected by panic induction with 50 microg cholecystokinin-tetrapeptide (CCK4) in healthy volunteers. J Psychiatr Res 2004;38:215-217.

50 Koszycki D, Zacharko RM, Le Mellédo JM, Bradwejn J: Behavioral, cardiovascular, and neuroendocrine profiles following CCK-4 challenge in healthy volunteers: a comparison of panickers and nonpanickers. Depress Anxiety 1998;8:1-7.

51 Eser D, di Michele F, Zwanzger P, PasiniA, Baghai TC, Schule C, Rupprecht R, Romeo E: Panic induction with cholecystokinin-tetrapeptide (CCK-4) increases plasma concentrations of the neuroactive steroid $3 \alpha, 5 \alpha$ tetrahydrodeoxycorticosterone $\quad(3 \alpha, 5 \alpha$ THDOC) in healthy volunteers. Neuropsychopharmacology 2005;30:192-195.

52 Purdy RH, Morrow AL, Moore PH, Paul SM: Stress-induced elevations of $\gamma$-aminobutyric acid type A receptor-active steroids in the rat brain. Proc Natl Acad Sci USA 1991;8:45534557.

53 Dong E, Matsumoto K, Uzunova V, Sugaya I, Takahata H, Nomura H, Watanabe H, Costa E, Guidotti A: Brain 5 $\alpha$-dihydroprogesterone and allopregnanolone synthesis in a mouse model of protracted social isolation. Proc Natl Acad Sci USA 2001;98:28492854. 
54 Matsumoto K, Uzunova V, Pinna G, Taki K, Uzunov DP, Watanabe $H$, Mienville JM, Guidotti A, Costa E: Permissive role of brain allopregnanolone content in the regulation of pentobarbital-induced righting reflex loss. Neuropharmacology 1999;38:955-963.

55 Guidotti A, Dong E, Matsumoto K, Pinna G, Rasmusson AM, Costa E: The socially-isolated mouse: a model to study the putative role of allopregnanolone and $5 \alpha$-dihydroprogesterone in psychiatric disorders. Brain Res Brain Res Rev 2001;37:110-115.

56 Uzunova V, Ceci M, Kohler C, Uzunov DP, Wrynn AS: Region-specific dysregulation of allopregnanolone brain content in the olfactory bulbectomized rat model of depression. Brain Res 2003;976:1-8.

57 Romeo E, Ströhle A, Spalletta G, di Michele F, Hermann B, Holsboer F, Pasini A, Rupprecht R: Effects of antidepressant treatment on neuroactive steroids in major depression. Am J Psychiatry 1998;155:910-913.

58 Uzunova V, Sheline Y, Davis JM, Rasmusson A, Uzunov DP, Costa E, Guidotti A: Increase in the cerebrospinal fluid content of neurosteroids in patients with unipolar major depression who are receiving fluoxetine or fluvoxamine. Proc Natl Acad Sci USA 1998;95: 3239-3244.

59 Ströhle A, Pasini A, Romeo E, Hermann B, Spalletta G, di Michele F, Holsboer F, Rupprecht R: Fluoxetine decreases concentrations of $3 \alpha, 5 \alpha$-tetrahydrodeoxycorticosterone (THDOC) in major depression. J Psychiatr Res 2000;34:183-186.

60 Meieran SE, Reus VI, Webster R, Shafton R, Wolkowitz OM: Chronic pregnenolone effects in normal humans: attenuation of benzodiazepine-induced sedation. Psychoneuroendocrinology 2003;29:486-500.

61 Wolkowitz OM, Reus VI, Roberts E, Manfredi F, Chan T, Raum WJ, Ormiston S, Johnson R, Canick J, Brizendine L, Weingartner $\mathrm{H}$ : Dehydroepiandrosterone (DHEA) treatment of depression. Biol Psychiatry 1997;41: 311-318.

62 Bloch M, Schmidt PJ, Danaceau MA, Adams LF, Rubinow DR: Dehydroepiandrosterone treatment of midlife dysthymia. Biol Psychiatry 1999;45:1533-1541.

63 Wolkowitz OM, Reus VI, Keebler A, Nelson $\mathrm{N}$, Friedland M, Brizendine L, Roberts E: Double-blind treatment of major depression with dehydroepiandrosterone. Am J Psychiatry 1999;156:646-649.

64 Schmidt PJ, Daly RC, Bloch M, Smith MJ, Danaceau MA, St Clair LS, Murphy JH, Haq N, Rubinow DR: Dehydroepiandrosterone monotherapy in midlife-onset major and minor depression. Arch Gen Psychiatry 2005;62:154-162.
65 Strous RD, Maayan R, Lapidus R, Stryjer R, Lustig M, Kotler M, Weizman A: Dehydroepiandrosterone augmentation in the management of negative, depressive, and anxiety symptoms in schizophrenia. Arch Gen Psychiatry 2003;60:133-141.

66 Friess E, Tagaya H, Trachsel L, Holsboer F, Rupprecht R: Progesterone-induced changes in sleep in male subjects. Am J Physiol 1997; 272:E885-E891.

67 Dennerstein L, Spencer-Gardner C, Gotts G, Brown JB, Smith MA, Burrows GD: Progesterone and the premenstrual syndrome: a double blind crossover trial. Br Med J 1980; 290:1617-1621.

68 Baker ER, Best RG, Manfredi RL, Demers LM, Wolf GC: Efficacy of progesterone vaginal suppositories in alleviation of nervous symptoms in patients with premenstrual syndrome. J Assist Reprod Genet 1995;12: 205-209.

69 Magill PJ: Investigation of the efficacy of progesterone pessaries in the relief of symptoms of premenstrual syndrome. Progesterone Study Group. Br J Gen Pract 1995;45: 589-593.

70 Freeman E, Rickels K, Sondheimer SJ, Polansky $\mathrm{M}$ : Ineffectiveness of progesterone suppository treatment for premenstrual syndrome. JAMA 1990;264:349-353.

71 Vanselow W, Dennerstein L, Greenwood KM, de Lignieres B: Effect of progesterone and its $5 \alpha$ and $5 \beta$ metabolites on symptoms of premenstrual syndrome according to route of administration. J Psychosom Obstet Gynaecol 1996;17:29-38.

72 Freeman EW, Rickels K, Sondheimer SJ, Polansky M: A double-blind trial of oral progesterone, alprazolam, and placebo in treatment of severe premenstrual syndrome. JAMA 1995;274:51-57.

73 Dalton K: Successful prophylactic progesterone for idiopathic postnatal depression. Int J Prenatal Perinatal Stud 1989;1:323-327.

74 Lawrie TA, Hofmeyr GJ, De Jager M, Berk M, Paiker J, Viljoen E: A double-blind randomised placebo controlled trial of postnatal norethisterone enanthate: the effect on postnatal depression and serum hormones. $\mathrm{Br} \mathrm{J}$ Obstet Gynaecol 1998;105:1082-1090.

75 Lawrie TA, Herxheimer A, Dalton K: Oestrogens and progestogens for preventing and treating postnatal depression. Cochrane $\mathrm{Da}$ tabase Syst Rev 2000;CD001690.

76 Uzunova V, Wrynn AS, Kinnunen A, Ceci M, Kohler C, Uzunov DP: Chronic antidepressants reverse cerebrocortical allopregnanolone decline in the olfactory-bulbectomized rat. Eur J Pharmacol 2004;486:31-34.
77 Uzunov DP, Cooper TB, Costa E, Guidotti A: Fluoxetine-elicited changes in brain neurosteroid content measured by negative ion mass fragmentography. Proc Natl Acad Sci USA 1996;93:12599-12604.

78 Serra M, Pisu MG, Muggironi M, Parodo V, Papi G, Sari R, Dazzi L, Spiga F, Purdy RH, Biggio G: Opposite effects of short- versus long-term administration of fluoxetine on the concentrations of neuroactive steroids in rat plasma and brain. Psychopharmacology 2001;158:48-54.

79 Griffin LD, Mellon SH: Selective serotonin reuptake inhibitors directly alter activity of neurosteroidogenic enzymes. Proc Natl Acad Sci USA 1999;96:13512-13517.

80 Trauger JW, Jiang A, Stearns BA, LoGrasso PV: Kinetics of allopregnanolone formation catalyzed by human $3 \alpha$-hydroxysteroid dehydrogenase type III (AKR1C2). Biochemistry 2002;41:13451-13459.

81 Serra M, Pisul MG, Dazzi L, Purdy RH, Biggio G: Prevention of the stress-induced increase in the concentration of neuroactive steroids in rat brain by long-term administration of mirtazapine but not of fluoxetine. J Psychopharmacol 2002;16:133-138.

82 Schule C, Romeo E, Uzunov DP, Eser D, di Michele F, Baghai TC, Pasini A, Schwarz M, Kempter H, Rupprecht R: Influence of mirtazapine on plasma concentrations of neuroactive steroids in major depression and on $3 \alpha$-hydroxysteroid dehydrogenase activity. Mol Psychiatry 2006;11:261-272.

83 Schule C, di Michele F, Baghai T, Romeo E, Bernardi G, Zwanzger P, Padberg F, Pasini A Rupprecht R: Influence of sleep deprivation on neuroactive steroids in major depression. Neuropsychopharmacology 2003;28:577581.

84 Padberg F, di Michele F, Zwanzger P, Romeo E, Bernardi G, Schule C, Baghai TC, Ella R, Pasini A, Rupprecht R: Plasma concentrations of neuroactive steroids before and after repetitive transcranial magnetic stimulation (rTMS) in major depression. Neuropsychopharmacology 2002;27:874-878.

85 Baghai TC, di Michele F, Schule C, Eser D, Zwanzger P, Pasini A, Romeo E, Rupprecht $\mathrm{R}$ : Plasma concentrations of neuroactive steroids before and after electroconvulsive therapy in major depression. Neuropsychopharmacology 2005;30:1181-1186.

86 Papadopoulos V, Lecanu L, Brown RC, Han Z, Yao ZX: Peripheral-type benzodiazepine receptor in neurosteroid biosynthesis, neuropathology and neurological disorders. Neuroscience 2005;138:749-756

87 Kita A, Kohayakawa H, Kinoshita T, Ochi Y, Nakamichi K, Kurumiya S, Furukawa K, Oka M: Antianxiety and antidepressant-like effects of AC-5216, a novel mitochondrial benzodiazepine receptor ligand. Br J Pharmacol 2004;142:1059-1072. 